\section{Case Reports in Neurology}

Case Rep Neurol 2020;12:169-175

DOI: $10.1159 / 000507953$

Published online: December 14, 2020
(C) 2020 The Author(s)

Published by S. Karger AG, Basel www.karger.com/crn

This article is licensed under the Creative Commons Attribution-NonCommercial 4.0 International License (CC BY-NC) (http://www.karger.com/Services/OpenAccessLicense). Usage and distribution for commercial purposes requires written permission.

\title{
Subarachnoid Hemorrhage due to Ruptured Spinal Artery Aneurysm: A Diagnostic Challenge
}

\author{
Ngoc Hoang Nguyen ${ }^{a}$ Vien Chi Le ${ }^{a} \quad$ Trung Quoc Nguyen $^{b}$ \\ Thang Huy Nguyen ${ }^{\text {b, c }}$ \\ a Stroke Center, 108 Military Central Hospital, Ha Noi, Vietnam; ${ }^{b}$ Cerebrovascular Disease \\ Department, People's Hospital 115, Ho Chi Minh City, Vietnam; 'Pham Ngoc Thach \\ University of Medicine, Ho Chi Minh City, Vietnam
}

\section{Keywords}

Spinal aneurysm $\cdot$ Subarachnoid hemorrhage $\cdot$ Radiculomedullary artery

\begin{abstract}
Subarachnoid hemorrhage $(\mathrm{SAH})$ due to a solitary spinal aneurysm is extremely rare. Early diagnosis of spinal SAH is challenging, particularly when the spinal cord has not been compressed. We report a case of a 45-year-old male who presented with sudden onset of abdominal pain, followed by severe headache, vomiting, and generalized seizure. Three days after admission to the hospital, he developed progressive paraparesis. Magnetic resonance imaging (MRI) revealed spinal SAH with hematoma resulting in cord compression at the level of T9. Diagnostic spinal angiography identified a ruptured aneurysm of a radiculomedullary artery. In conclusion, rupture of a spinal aneurysm should be considered a possible cause of SAH in appropriate clinical settings, and clinicians must be aware of the possibility of cord compression.




\section{Case Reports in Neurology}

Case Rep Neurol 2020;12:169-175

DOI: 10.1159/000507953

(c) 2020 The Author(s). Published by S. Karger AG, Basel www.karger.com/crn

Nguyen et al:: Subarachnoid Hemorrhage due to Ruptured Spinal Artery Aneurysm: A Diagnostic Challenge

\section{Introduction}

Subarachnoid hemorrhage (SAH) of spinal origin is a rare event, representing less than $1 \%$ of all cases of SAH reported in the literature $[1,2]$. Most reports of spinal aneurysms involved single cases or small case series [3-6, 9]. The epidemiology, appropriate management strategy, obliteration rate, and outcome are largely unknown. Without cord compression, the clinical symptoms of spinal SAH are generally similar to intracranial SAH. Spinal cord compression due to spinal SAH is relatively infrequent because the cerebrospinal fluid tends to dilute the hemorrhage and prevent clot formation. However, spinal SAH should be diagnosed as soon as possible to avoid the complication of cord compression.

\section{Case Presentation}

A 45-year-old male presented with sudden onset of abdominal pain, followed by severe headache, vomiting, and generalized seizure. His medical history was otherwise unremarkable. On clinical examination, neck stiffness was found without any neurological deficits. On admission, non-enhanced head computed tomography (CT) revealed SAH involving the cortical parietal sulci (Fig. 1a). Intracranial CT angiography did not reveal any abnormality. Cerebrospinal fluid study was positive for SAH. Three days after admission to the hospital he developed progressive paraparesis more severely involving the right leg, with a sensory level below T9. With the suspicion of spinal hemorrhage, a spinal magnetic resonance imaging (MRI) study was acquired, revealing intradural bleeding with an 8-mm contrast-enhancing nodular lesion at the level of T9. Maximum cord deformity was seen at T9 level with spinal cord edema (Fig. 2). Spinal angiography was performed on the following day to look for a vascular pathology. Selective injection of the left T10 intercostal artery revealed a $2.5 \times 3.4 \mathrm{~mm}$ aneurysm in the intradural segment of a radiculomedullary artery (Fig. 3, online suppl. DSA video; for all online suppl. material, see www.karger.com/doi/10.1159/000507953). No other vascular anomalies were seen. Based on the findings, a neurosurgical consultation recommended laminoplasty and microsurgical resection of the ruptured aneurysm. At 5-month telephone follow-up, he had a moderate degree of clinical improvement. The motor strength of bilateral lower limbs was 3/5. It recovered incompletely in terms of sensation. He had no bowel or bladder incontinence but was using a wheelchair. His modified Rankin Score was 4.

\section{Discussion}

Multiple reports suggest that less than 1\% of SAHs result from rupture of spinal aneurysms [1]. Aneurysm associated with spinal arteriovenous malformation is the most common cause of spinal SAH. Other known conditions associated with spinal aneurysm include arterial dissection, neoplasm, systemic lupus erythematosus, moyamoya disease, fibromuscular dysplasia, pregnancy, and infection $[1,2]$. Rupture of spinal aneurysms may present as SAH or cord compression. As compared to intracranial SAH, spinal SAH poses more diagnostic challenges, particularly when the spinal cord has not been compressed or the lesions are located low in the lumbar region. In a review of spinal SAH, Maiti et al. [1] commented that neuroradiologic diagnosis of spinal SAH was extremely difficult, and most of the earlier cases were diagnosed at autopsy or after surgical exploration [9]. In this report, our patient presented with

\section{Karger'=}




\section{Case Reports in Neurology}

Case Rep Neurol 2020;12:169-175

DOI: 10.1159/000507953

(c) 2020 The Author(s). Published by S. Karger AG, Basel www.karger.com/crn

Nguyen et al:: Subarachnoid Hemorrhage due to Ruptured Spinal Artery Aneurysm: A Diagnostic Challenge

signs and symptoms suggestive of a $\mathrm{SAH}$, but when first seen it was difficult to attribute his symptoms to an anterior spinal artery aneurysm. He did complain of abdominal pain, followed by severe headache, vomiting, generalized seizure, and the clinical finding of neck stiffness. However, suspicion of spinal hemorrhage was raised only after the patient developed progressive paraparesis. The symptoms of ruptured spinal aneurysm seem to correlate with the level of the lesion. Ruptured aneurysm at the cervical level can cause meningeal irritation due to intracranial SAH or quadriparesis [5]. Lesions involving the thoracolumbar levels can cause lower back pain, abdominal pain, and motor weakness or sensory changes of the lower extremities [7]. The sequence of back pain followed by headache is the hallmark of SAH in the thoracic region. Minor SAH can present predominantly as radicular pain often mistaken as a lower motor neuron condition. Associated headache, nausea, vomiting, and neck stiffness may be the clues to spinal SAH in these patients. Rupture of a spinal artery aneurysm should be considered when there are spinal symptoms with SAH and no other source of bleeding is identified in brain imaging, and/or when the hemorrhage is limited to or predominantly present in the spine. A complete spinal MRI including dynamic contrast-enhanced MR angiography and post contrast sequences should be performed. CT angiography may also be performed to better visualize the relation between the aneurysm and the spinal canal. Spinal angiography is the gold standard for the detection and characterization of spinal aneurysms, and is usually required for further management $[1,8]$. There is no standard treatment guideline for ruptured spinal aneurysms as these lesions are very rare. Therefore, the choice among different treatment modalities, including surgery, endovascular embolization, and conservative management, remains controversial $[1,3,10,11]$. Surgical approach is more commonly employed in posteriorly localized aneurysms due to their dorsolateral and superficial location [6]. The mass effect of the aneurysm or the blood clot may be an indication for microsurgery [1]. In our case, the progressive paraparesis due to cord compression was the indication for surgical resection.

In conclusion, rupture of an isolated spinal aneurysm is a rare cause of SAH. When spinal SAH is present in appropriate clinical settings, isolated spinal artery aneurysm should be considered as a possible and treatable cause.

\section{Acknowledgement}

Thao D Ta treated the patient and provided patient data.

\section{Statement of Ethics}

Written informed consent was obtained from the patient for publication of this case report and any accompanying images. The research was conducted ethically in accordance with the World Medical Association Declaration of Helsinki.

\section{Conflict of Interest Statement}

The authors have no conflicts of interest to declare.

\section{Karger'}




\section{Case Reports in Neurology}

\begin{tabular}{l|l}
\hline Case Rep Neurol 2020;12:169-175 \\
\hline DOI: $10.1159 / 000507953$ & $\begin{array}{l}\text { (c) 2020 The Author(s). Published by S. Karger AG, Basel } \\
\text { www.karger.com/crn }\end{array}$ \\
\hline
\end{tabular}

Nguyen et al:: Subarachnoid Hemorrhage due to Ruptured Spinal Artery Aneurysm: A Diagnostic Challenge

\section{Funding Sources}

The authors received no financial support for the research, authorship, and publication of this article.

\section{Author Contributions}

Ngoc Hoang Nguyen and Vien Chi Le were major contributors in writing the manuscript and performing the literature review. Trung Quoc Nguyen made substantial contributions to revise the manuscript. Thang Huy Nguyen interpreted the patient data and was a major contributor in writing the manuscript. All authors read and approved the final manuscript.

\section{References}

1 Maiti TK, Bir SC, Nanda A. Spinal subarachnoid hemorrhage and aneurysms. Handb Clin Neurol. 2017;143:215-23.

2 Madhugiri VS, Ambekar S, Roopesh Kumar VR, Sasidharan GM, Nanda A. Spinal aneurysms: clinicoradiological features and management paradigms. J Neurosurg Spine. 2013 Jul;19(1):34-48.

3 Gutierrez Romero D, Batista AL, Gentric JC, Raymond J, Roy D, Weill A. Ruptured isolated spinal artery aneurysms. Report of two cases and review of the literature. Interv Neuroradiol. 2014 Dec;20(6):774-80.

4 Rengachary SS, Duke DA, Tsai FY, Kragel PJ. Spinal arterial aneurysm: case report. Neurosurgery. 1993 Jul;33(1):125-9; discussion 129-30.

5 Donauer E, Aguilar Pérez M, Jangid N, Tomandl B, Ganslandt O, Henkes H. Spontaneous Cervical Intramedullary and Subarachnoid Hemorrhage due to a Sulco-Commissural Artery Aneurysm. Clin Neuroradiol. 2019 Mar;29(4):777-81.

6 Smith BS, Penka CF, Erickson LS, Matsuo F. Subarachnoid hemorrhage due to anterior spinal artery aneurysm. Neurosurgery. 1986 Feb;18(2):217-9.

7 Berlis A, Scheufler KM, Schmahl C, Rauer S, Götz F, Schumacher M. Solitary spinal artery aneurysms as a rare source of spinal subarachnoid hemorrhage: potential etiology and treatment strategy. AJNR Am J Neuroradiol. 2005 Feb;26(2):405-10.

8 Koc 0, Ozbek 0, Paksoy Y, Kocaogullari Y. Anterior spinal artery aneurysm presenting with spinal cord compression: MRI and MRI angiographic findings. J Neurol Neurosurg Psychiatry. 2010 Jul;81(7):771-2.

9 Domenicucci M, Ramieri A, Paolini S, Russo N, Occhiogrosso G, Di Biasi C, et al. Spinal subarachnoid hematomas: our experience and literature review. Acta Neurochir (Wien). 2005 Jul;147(7):741-50; discussion 750.

10 Rothrock RJ, Li AY, Rumsey J, Fifi JT, Kellner CP, Roonprapunt C. Aneurysmal Subarachnoid Hemorrhage with Spinal Subdural Hematoma: A Case Report and Systematic Review of the Literature. World Neurosurg. 2019 Aug;128:240-7.

11 Son S, Lee SG, Park CW. Solitary ruptured aneurysm of the spinal artery of adamkiewicz with subarachnoid hemorrhage. J Korean Neurosurg Soc. 2013 Jul;54(1):50-3. 
Case Reports in Neurology
Case Rep Neurol 2020;12:169-175 DOI: 10.1159/000507953

(c) 2020 The Author(s). Published by S. Karger AG, Basel www.karger.com/crn

Nguyen et al:: Subarachnoid Hemorrhage due to Ruptured Spinal Artery Aneurysm: A Diagnostic Challenge

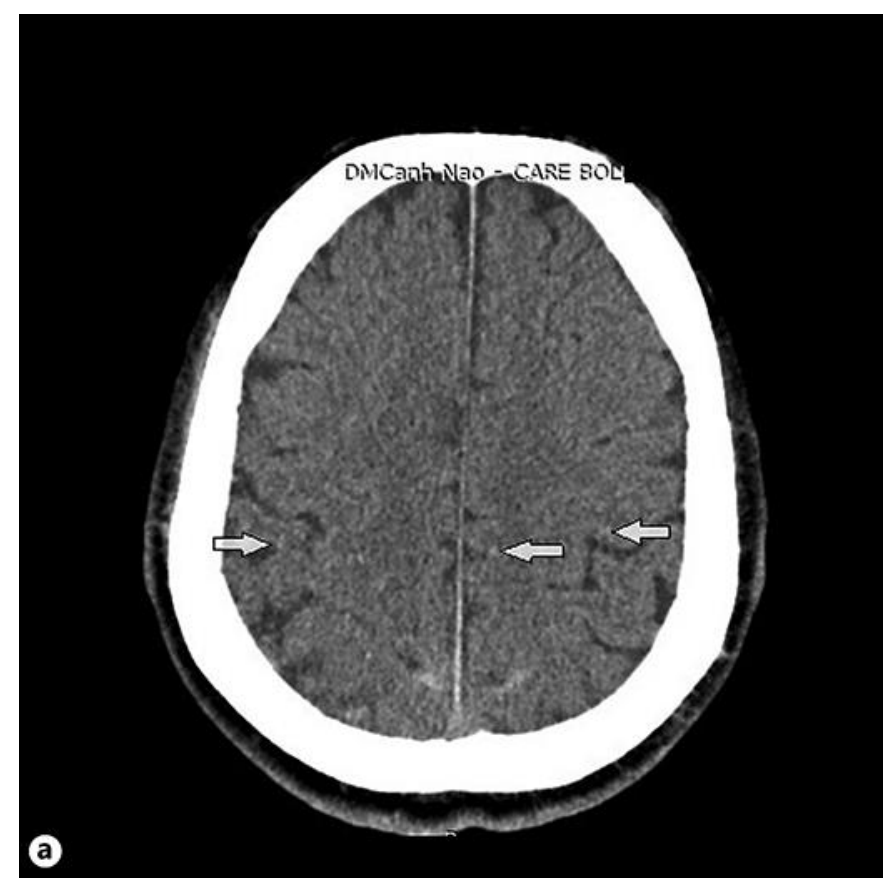

Fig. 1. Non-enhanced head CT scan. Axial slice showing hyperdense parietal cortical sulci, corresponding to SAH. 
Case Reports in Neurology

\begin{tabular}{l|l}
\hline Case Rep Neurol 2020;12:169-175 \\
\hline DOI: 10.1159/000507953 & $\begin{array}{l}\text { @ 2020 The Author(s). Published by S. Karger AG, Basel } \\
\text { www.karger.com/crn }\end{array}$ \\
\hline
\end{tabular}

Nguyen et al.: Subarachnoid Hemorrhage due to Ruptured Spinal Artery Aneurysm: A Diagnostic Challenge
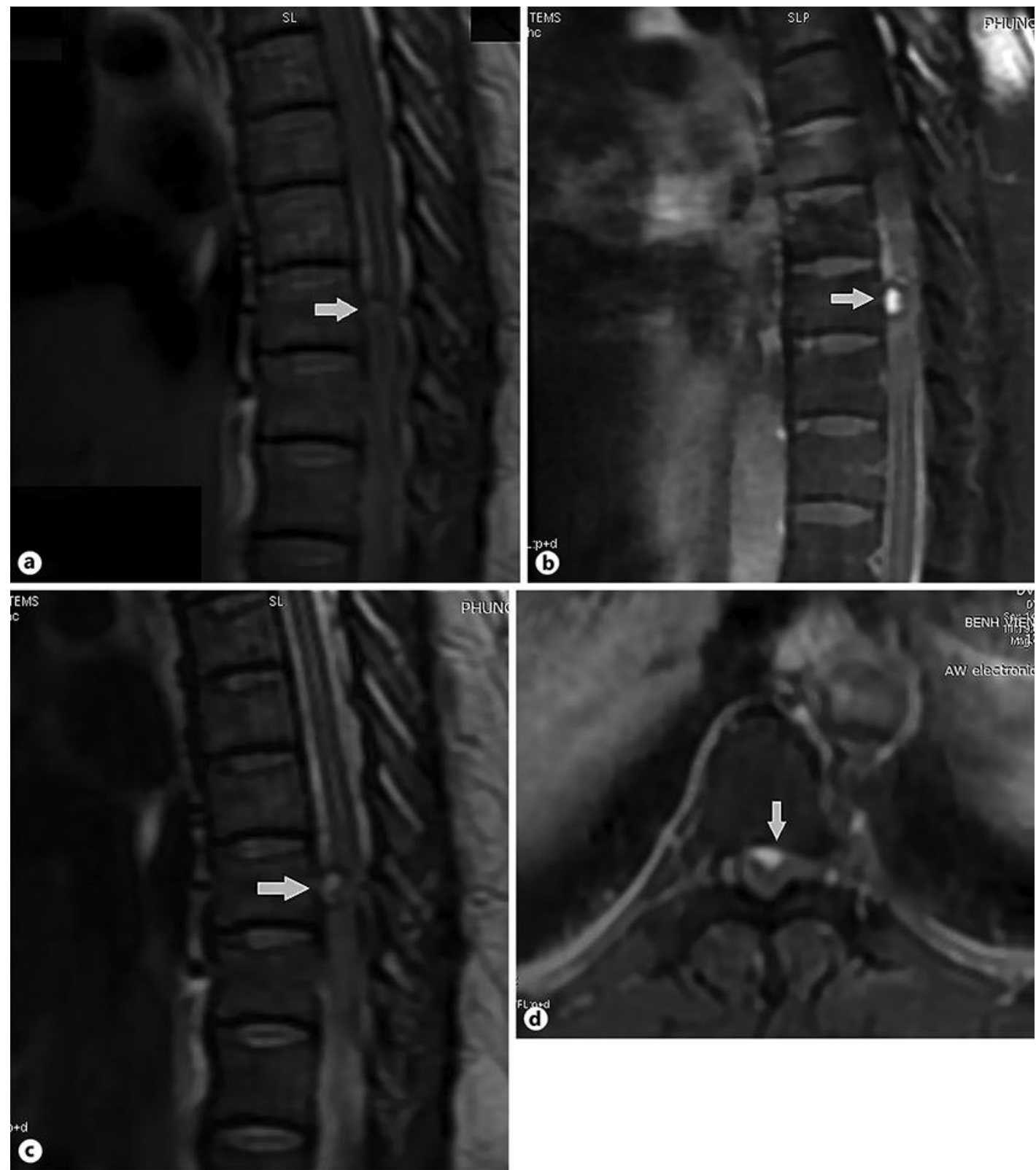

Fig. 2. A nodular lesion the T9 level (arrow) with iso-intense signal on T1-weighted sagittal images (a) and hyper-intense signal on both T2-weighted images (c) as well as contrast-enhanced T1-weighted images (b, d). 
Case Reports in Neurology
Case Rep Neurol 2020;12:169-175

DOI: 10.1159/000507953

(c)

2020 The Author(s). Published by S. Karger AG, Basel

Nguyen et al.: Subarachnoid Hemorrhage due to Ruptured Spinal Artery Aneurysm: A Diagnostic Challenge

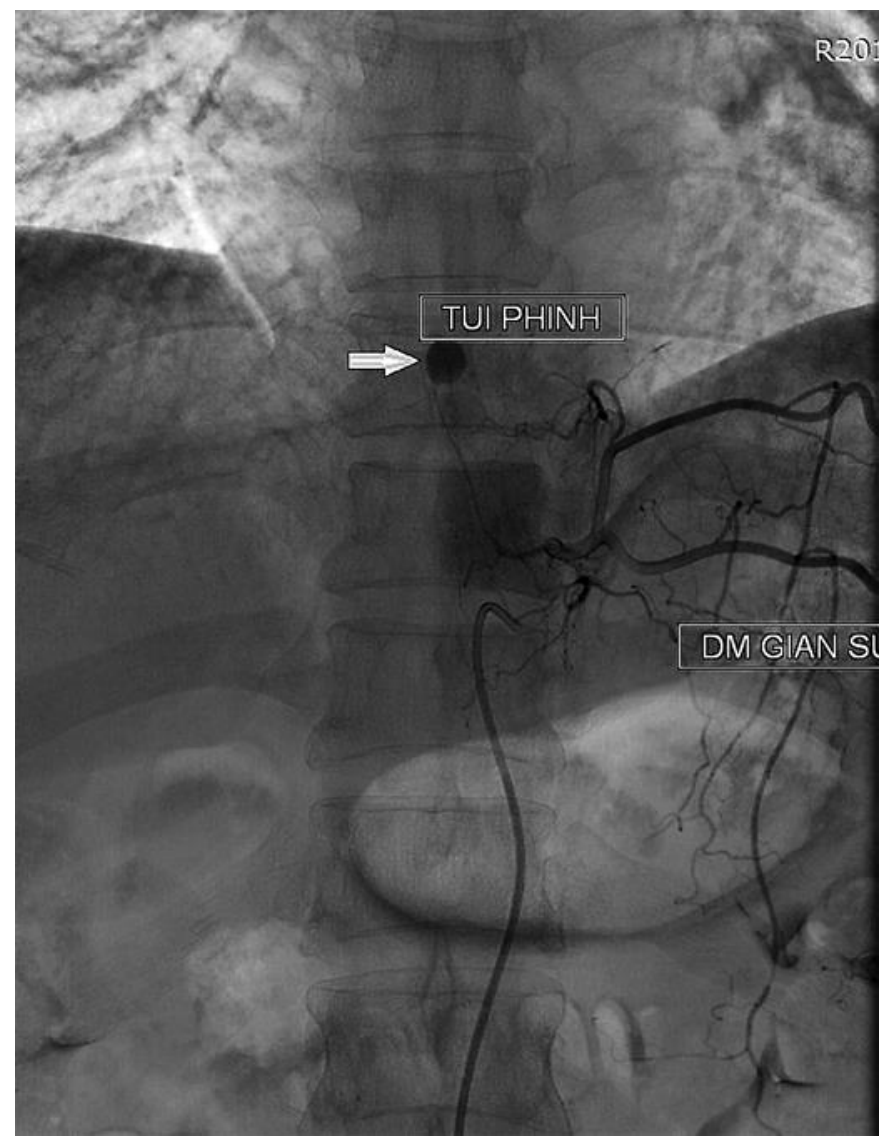

Fig. 3. Selective injection of the left T10 intercostal artery revealed an isolated aneurysm (arrow) in the intradural segment of a radiculomedullary artery. 